\title{
Article \\ Salinity Eustress Increases the Biosynthesis and Accumulation of Phenolic Compounds That Improve the Functional and Antioxidant Quality of Red Lettuce
}

\author{
Christian Santander ${ }^{1,2} \mathbb{D}$, Gladys Vidal ${ }^{1, *(\mathbb{D})}$, Antonieta Ruiz ${ }^{2} \mathbb{D}$, Catalina Vidal ${ }^{2}$ and Pablo Cornejo ${ }^{2, *}(\mathbb{D}$ \\ 1 Environmental Engineering and Biotechnology Group, Faculty of Environmental Sciences and EU-LA-Chile \\ Center, Universidad de Concepción, Concepción 4070411, Chile; c.santander01@ufromail.cl \\ 2 Center for Research on Mycorrhizae and Agro-Environmental Sustainability (CIMYSA), Universidad de la \\ Frontera, Temuco 4780000, Chile; maria.ruiz@ufrontera.cl (A.R.); catalinavidalp@gmail.com (C.V.) \\ * Correspondence: glvidal@udec.cl (G.V.); pablo.cornejo@ufrontera.cl (P.C.)
}

check for updates

Citation: Santander, C.; Vidal, G.; Ruiz, A.; Vidal, C.; Cornejo, P. Salinity Eustress Increases the Biosynthesis and Accumulation of Phenolic Compounds That Improve the Functional and Antioxidant Quality of Red Lettuce. Agronomy 2022, 12, 598. https://doi.org/10.3390/ agronomy12030598

Academic Editor: Nikos Tzortzakis

Received: 25 January 2022

Accepted: 24 February 2022

Published: 27 February 2022

Publisher's Note: MDPI stays neutral with regard to jurisdictional claims in published maps and institutional affiliations.

Copyright: (C) 2022 by the authors. Licensee MDPI, Basel, Switzerland. This article is an open access article distributed under the terms and conditions of the Creative Commons Attribution (CC BY) license (https:// creativecommons.org/licenses/by/ $4.0 /)$.

\begin{abstract}
The application of different techniques of positive stress (eustress), such as mild and moderate saline stress, could enhance the nutritional and functional attributes of food vegetables. The present study aimed to evaluate the positive effect of salinity as a eustressor on the functional quality of red lettuce growing under hydroponic conditions and subjected to increasing salinity. Red lettuce plants were grown for 60 days and, 45 days after sowing, were subjected to different levels of salinity $(0,50,100,150$, and $200 \mathrm{mM} \mathrm{NaCl})$. The phenolic compound concentration and antioxidant activity were measured at 7 and 15 days after the application of salinity treatment. Moreover, at harvest, the root and shoot biomass and efficiency of photosystem II were evaluated. Our results showed that the highest phenolic concentration and antioxidant activity were obtained through moderate salt stress $(50 \mathrm{mM} \mathrm{NaCl})$ applied for 15 days without affecting the photosynthetic activity and biomass production of lettuce plants. By contrast, when severe salt stress levels (150-200 $\mathrm{mM} \mathrm{NaCl}$ ) were applied, an increase in phenolic compounds was also obtained, but concomitantly with a significant reduction in antioxidant activity and biomass production. The application of moderate stress in red lettuce suggests its potential use as a tool to increase the biosynthesis and accumulation of bioactive secondary metabolites, improving the nutritional characteristics of red lettuce.
\end{abstract}

Keywords: bioactive compounds; Lactuca sativa; saline stress; secondary metabolism

\section{Introduction}

Consuming a diet rich in fruits and vegetables is associated with a reduced risk of noncommunicable disease [1]. These beneficial effects are believed to be due to the presence of phytochemical compounds, defined as bioactive compounds, including polyphenols, carotenoids and vitamins, among others [2]. Since the overproduction of free radicals formed through cell metabolism are involved in the pathogenesis of numerous chronic diseases [3], the protective role of phytochemicals is associated with their antioxidant activity, mainly through their inhibition of the oxidative damage caused by reactive oxygen species (ROS) and reactive nitrogen species (RNS) [4].

Lettuce (Lactuca sativa L.) is a plant species representative of the Asteraceae family. It is an important leafy agricultural product and one of the most popular vegetables worldwide; it is currently consumed in increasing amounts due to its perception as a healthy food [3]. The consumption of lettuce provides an important source of different nutritionally valuable antioxidant substances, such as phenolic compounds (flavonoids and phenolic acids), vitamin C, and fiber contents [5]. Several studies have shown significant levels of antioxidant activity and phenolic compounds in lettuce [6-9]. Furthermore, caffeic acid derivatives and flavonoids have been demonstrated as the major phenolic compounds in lettuce plants $[10,11]$. Phenolic compounds are synthesized during normal plant growth 
and are overproduced in response to different types of environmental stresses, such as salinity and drought, among others [12].

The high amounts of salt concentrations (mainly $\mathrm{NaCl}$ ) in irrigation water and agricultural soils produce saline stress in plants, severely affecting their growth and, consequently, the crop yield and the quality of the final product [13]. One of the major consequences of saline stresses is oxidative stress mediated by increased levels of ROS, such as singlet oxygen $\left({ }^{1} \mathrm{O}_{2}\right)$, superoxide $\left(\mathrm{O}_{2}{ }^{\bullet-}\right)$, hydroxyl radical $\left(\mathrm{OH}^{\bullet}\right)$, and hydrogen peroxide $\left(\mathrm{H}_{2} \mathrm{O}_{2}\right)$, which have the potential to interact with many cellular components, causing significant damage to membranes and other cellular structures $[9,14]$. To cope with the harmful effects of salinity, plants synthesize a broad range of secondary metabolites to counteract oxidative damage and to scavenge ROS, particularly phenolic compounds [15]. Although salinity generally reduces crop productivity, in many cases, the application of positive stress in plants, also known as 'eustress', triggers defense mechanisms through the biosynthesis and accumulation of bioactive secondary metabolites [16]. According to Kyriacou and Rouphael [16], vegetable crops may show different responses to the application of eustress (mild-to-moderate salinity) because of the stress-induced reshuffling of plant metabolism, which increases the accumulation of bioactive compounds and enriches the functional quality of fresh vegetables to the benefit of the human diet. Similarly, salinity stress applications can be easily applied by managing the electrical conductivity of water in hydroponic systems [17], and could assist in the use of extensive lands subjected to salinity worldwide.

Based on the need to maximize the production of vegetable foods to improve global food security, the demand for high-quality vegetable products is also increasing, mainly due to the interest of consumers in fresh products with high organoleptic, nutritional, and functional quality. Therefore, the application of eustressors such as salinity may be an effective strategy to modulate the active compounds in vegetable crops, offering valuable and sustainable tools for the manipulation of the phytochemical contents and functional properties of plant foods. Considering this background, the main objective of this work was to study the positive effect of moderate levels of salinity as a potential eustressor on the functional quality of red lettuce grown under hydroponic conditions by means of the composition changes of phenolic acids, flavonoids, and antioxidant activity, as well as the effects on the photosynthetic activity and biomass production, thereby finding the right eustress level to improve lettuce quality without compromising crop yield.

\section{Materials and Methods}

\subsection{Growth Conditions, Biological Material, and Experimental Design}

The experiment was carried out over 60 days under greenhouse conditions with temperatures of $20 / 25{ }^{\circ} \mathrm{C}$ night/day, respectively, $50-70 \%$ relative humidity and a $16 / 8 \mathrm{~h}$ light/dark photoperiod (Department of Chemical Sciences and Natural Resources, University of La Frontera, Temuco, Chile). The crop studied was Lactuca sativa L. var. acephala cv. Lollo Rosso 'CARMOLI' (RijkZwaan, Santiago, Chile), which was selected based on its frequent use in hydroponic production for the Chilean market. Seeds were sown in polystyrene trays with perlite as substrate and the seedlings were maintained for 15 days. Next, the seedlings with robust growth were transferred to the floating hydroponic system with continuous aeration (plastic boxes: $67 \mathrm{~cm}$ long, $40 \mathrm{~cm}$ wide, and $16 \mathrm{~cm}$ high), and containing $30 \mathrm{~L}$ of Hoagland's complete nutrient solution prepared with tap water [18], which was refreshed every 10 days with the $\mathrm{pH}$ maintained at 6.0. At 45 days after sowing (DAS), sodium chloride $(\mathrm{NaCl})$ was added to the nutrient solution in the form of a unique application at the following concentrations: $0 \mathrm{mM} \mathrm{NaCl}$ (control); $50 \mathrm{mM} \mathrm{NaCl} ; 100 \mathrm{mM}$ $\mathrm{NaCl} ; 150 \mathrm{mM} \mathrm{NaCl}$; and $200 \mathrm{mM} \mathrm{NaCl}$. These values corresponded to $0.9,6.5,11.6,16.4$, and $21.1 \mathrm{dS} \mathrm{m}^{-1}$ of electrical conductivity, respectively. Each hydroponic system was a saline treatment, and six lettuce plants $(n=6)$ were grown in each one $(n=30)$. 


\subsection{Biomass Production and Efficiency of Photosystem II}

After 15 days of exposure to salinity (60 DAS), the plants were harvested, the shoot and root organs were weighed, and subsamples $(5 \mathrm{~g})$ of fresh material were stored at $-80^{\circ} \mathrm{C}$ for biochemical analyses. Furthermore, at harvest, the efficiency of photosystem II ( $\Phi$ PSII) was measured in vivo with FluorPen FP100 (Photon Systems Instruments, Brno, Czech Republic) equipment $2 \mathrm{~h}$ after the onset of the photoperiod.

\subsection{Identification and Quantification of Phenolic Compounds}

The determination of phenolic compounds and antioxidant activity in the lettuce shoots was carried out at 52 and 60 days after sowing ( 7 and 15 days after salinity application). Phenolic compounds were extracted according to Santander et al. [9], with some modifications. Briefly, one-gram samples of fresh leaves were pulverized in liquid nitrogen, mixed with $8 \mathrm{~mL}$ of a mixture of $\mathrm{MeOH}$ :water:formic acid (25:24:3, v:v:v) followed by 1 min of ultrasonication with bar at $80 \%$ amplitude, shaken for two hours, and centrifuged at $4000 \times g$ for $20 \mathrm{~min}$. HPLC-DAD analyses were carried out using a Shimadzu HPLC system (Tokyo, Japan) equipped with a quaternary LC-20AT pump with a DGU-20A5R degassing unit, a CTO-20A oven, a SIL-20a autosampler, and an UV-vis diode array spectrophotometer (SPD-M20A). Instrument control and data collection were carried out using Lab Solutions (Shimadzu, Duisburg, Germany). Identity assignments were performed on an Agilent 1100 Series system (Agilent, Ratingen, Germany), equipped with DAD (G1315B) and LC/MSD Trap VL (G2445C VL) electrospray ionization mass spectrometry (ESI-MSn) system, and coupled to an Agilent Chem Station (version B.01.03) data-processing station. The chromatographic separation method (HPLC-DAD) for the determination of phenolic compounds was developed based on the procedure reported by Parada et al. [19], through the use of a Kromasil ClassicShell-2.5-C18 (Sigma Aldrich, St. Louis, MO, USA; $4.6 \times 100 \mathrm{~mm}, 2.5 \mu \mathrm{m}$ ) column and a C18 precolumn (Novapak, Waters, Milford, MA, USA, $22 \times 3.9 \mathrm{~mm}, 4 \mu \mathrm{m})$. The samples were injected using water:acetonitrile:formic acid (92:3:5, v:v:v) and water:acetonitrile:formic acid (45:50:5, v:v:v) as A and B mobile phases, respectively, with an elution gradient between 6 to $50 \%$ B over $30 \mathrm{~min}$ at $0.55 \mathrm{~mL} \mathrm{~min}^{-1}$ and $40{ }^{\circ} \mathrm{C}$.

Identities were assigned by comparison of the MS/MS spectra with those from the literature data and by comparison with commercial standards. MS/MS conditions were as follows: capillary temperature of $450{ }^{\circ} \mathrm{C}$, an auxiliary flow rate of 15 arbitrary units and $4000 \mathrm{~V}$ ionization voltage, with positive ionization for anthocyanins and negative ionization for the other phenolic compounds [20]. Flavonols and chicoric acid were quantified at $360 \mathrm{~nm}$ and chlorogenic acids at $320 \mathrm{~nm}$, using rutin ( $\geq 94 \%)$, chicoric acid $(\geq 95 \%)$, and 5caffeoylquinic acid ( $\geq 95 \%$ ) (Sigma-Aldrich, Steinheim, Germany), respectively, as external calibration standards. For the anthocyanin quantification, cyanidin-3-glucoside ( $\geq 98 \%)$ (Phytolab, Darmstadt, Germany) was used as standard for the external calibration.

\subsection{Total Phenols and Antioxidant Activity Determinations}

Total phenol concentration was determined by the Folin-Ciocalteu method, as described by Singleton and Rossi [21], and adapted to a microplate reader, as described in Parada et al. [19]. The absorbance was read at $750 \mathrm{~nm}$, and gallic acid was used as standard. Results were expressed as milligrams of gallic acid per gram of fresh weight (FW). The DPPH (2,2-diphenyl-1-picrylhydrazyl) activity was determined according to the methodology described by Parada et al. [19]. Measurements were performed at $517 \mathrm{~nm}$, and the results were expressed as Trolox equivalents.

\subsection{Statistics}

A fully randomized design with six replicates per treatment was established. Data sets were analyzed by means of one-way analysis of variance (ANOVA). Ln transformation was used when the data sets did not meet the ANOVA assumptions (homoscedasticity and normality); nevertheless, all results are expressed in their original scale of measurement. 
Tukey's multiple range post hoc test was used to compare the means of the treatments. Subsequently, data sets were also subjected to principal component (PC) analyses. Variability in the means was expressed as the standard error and a $p<0.05$ was considered statistically significant. IBM SPSS statistic Software v. 22.0 (Armonk, NY, USA) was used for all the statistical procedures.

\section{Results and Discussion}

Biomass production is a critical characteristic of plant production and is also an indicator of plant health [3]. At harvest time (60 DAS), the leaf and root fresh matter production and the number of leaves were negatively affected by the increasing salinity concentrations in the hydroponic solution (Figures 1 and 2). In detail, the plants subjected to 100,150 , and $200 \mathrm{mM} \mathrm{NaCl}$ (severe saline stress) showed a significant reduction in fresh leaf matter, with values ranging from 1.5-, 2.1-, and 2.9-fold, respectively, compared to the control plants. By contrast, the lettuce plants grown at $50 \mathrm{mM} \mathrm{NaCl}$ (moderate saline stress) reached the highest levels of leaf fresh matter production compared to all the plants subjected to salinity treatments; furthermore, no significant differences with respect to the control plants were registered (Figure 1a). According to Vázquez-Hernández et al. [22], the balance between the plant response (measured as yield, growth, quality, or tolerance) and sensitivity may determine whether a stressor has a positive or a negative effect on plant metabolism, ultimately determining the growth. Regarding the red lettuce plants subjected to 100,150, and $200 \mathrm{mM} \mathrm{NaCl}$ (severe saline stress), a significant reduction in leaf dry matter, with values ranging from 1.4-, 1.8-, and 2.2-fold, respectively, compared to the control plants (Figure 1c), was registered.

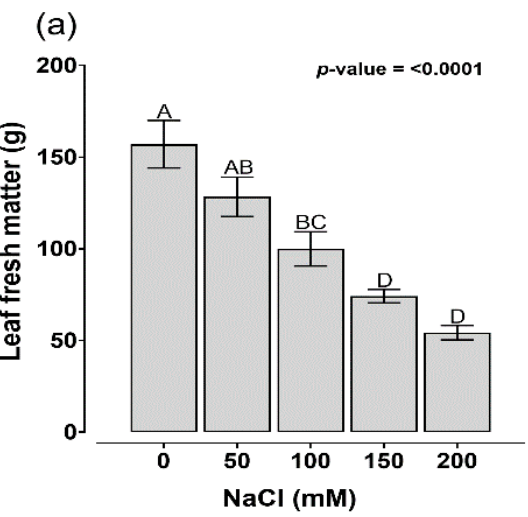

(c)

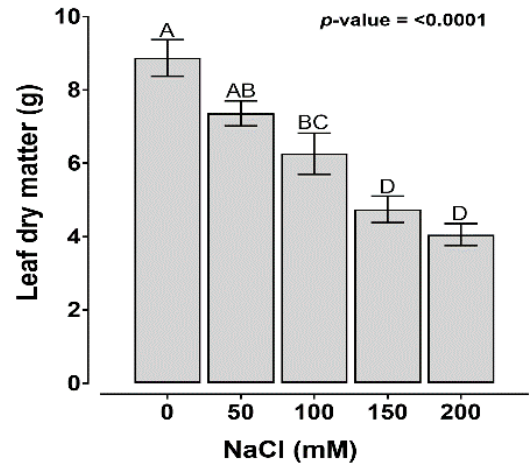

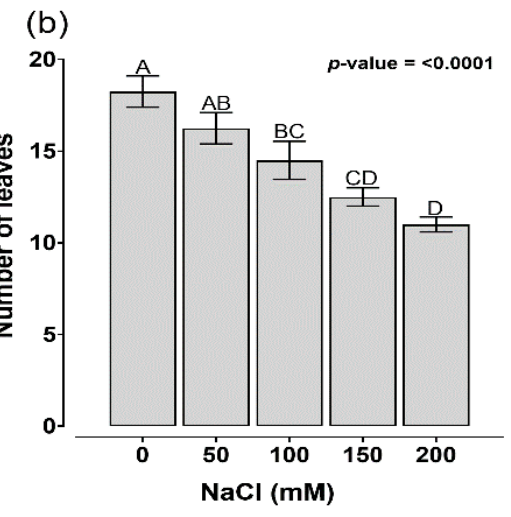

(d)

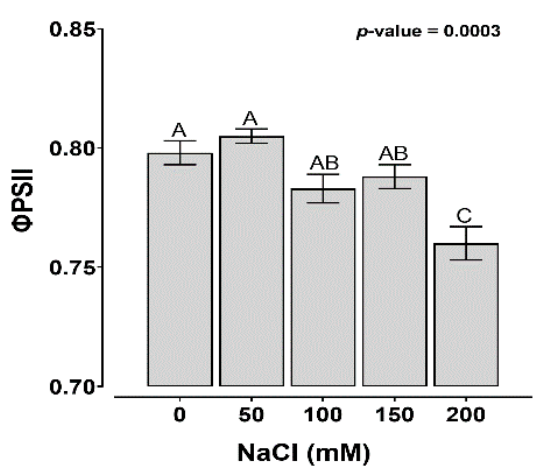

Figure 1. Production of fresh leaf matter (a), dry leaf matter (b), number of leaves (c), and efficiency of photosystem II (ФPSII) (d) in red lettuce plants (Lactuca sativa Lollo Rosso cv. 'CARMOLI') growing at increasing $\mathrm{NaCl}$ concentrations in a hydroponic system. Different letters indicate significant differences $(p<0.05)$, according to the Tukey multiple range test $(p<0.05)$ following ANOVA. Data are expressed as mean $\pm \mathrm{SE}, n=6$. 


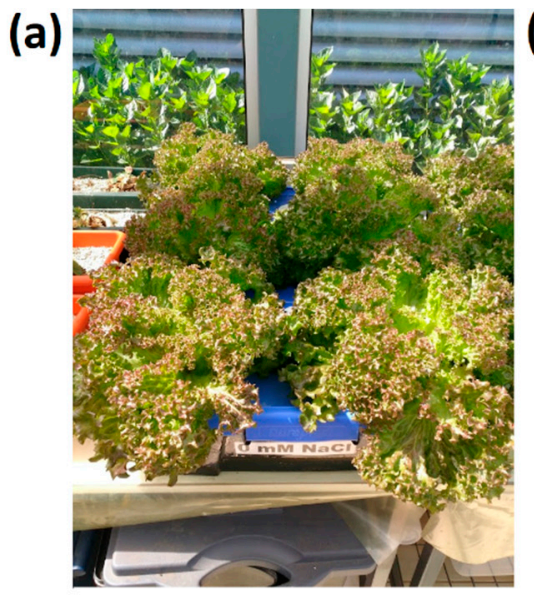

(d)

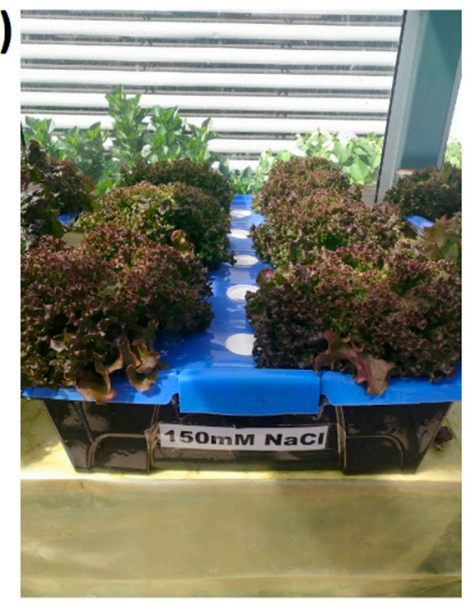

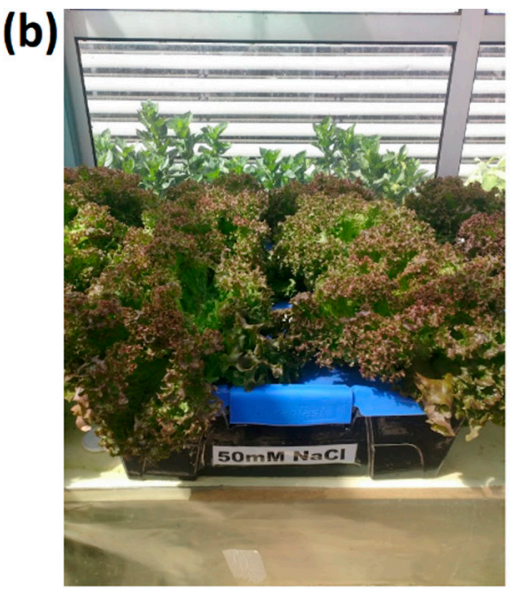

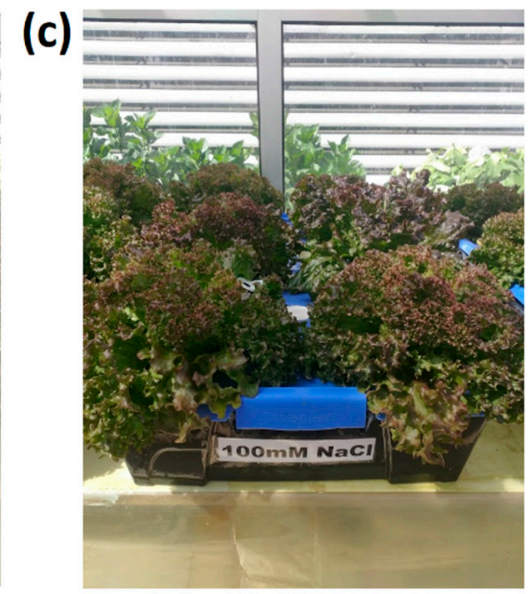

(e)

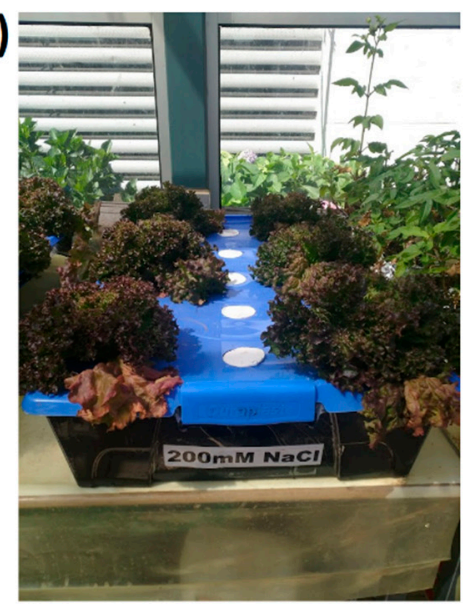

Figure 2. Morphological visual comparison of red lettuce plants (Lactuca sativa Lollo Rosso cv. 'CARMOLI') growing at: (a) $0 \mathrm{mM} \mathrm{NaCl}$, (b) $50 \mathrm{mM} \mathrm{NaCl}$, (c) $100 \mathrm{mM} \mathrm{NaCl}$, (d) $150 \mathrm{mM} \mathrm{NaCl}$, and (e) $200 \mathrm{mM} \mathrm{NaCl}$ in a hydroponic system.

In this regard, several studies have reported that high concentrations of Na in irrigation water diminish the biomass production of lettuce plants [9,23-26]. Salinity affects plant growth and development, which starts through a quicker response due to the osmotic effect; subsequently, a slower response caused by the toxic effect of salt accumulation in leaves takes place [27]. Consequently, the salt accumulation reduces photosynthetic activity, which also diminishes the supply of photosynthates and plant biomass production [28]. According to Saddiq et al. [29], salt stress has an adverse impact on photosynthesis by destroying chlorophyll pigments and inhibiting PSII activity; accordingly, in this study, the results showed that the efficiency of PSII was negatively affected at the highest salinity level $(200 \mathrm{mM} \mathrm{NaCl}$; Figure 1d). In fact, the measurement of chlorophyll fluorescence is an excellent indicator to quantify salt-induced destruction in the photosynthetic apparatus [30]. The excessive exposure of plants to salinity increases the production of ROS, which destroys thylakoid membranes and chlorophyll pigments, leading to the decreased activity of PSII [29].

Lettuce is an important vegetable source of phytonutrients with health-promoting properties, such as different phenolic compounds [31]. In this study, a total of six phenolic compounds were registered and quantified in red lettuce leaves based on their UV-visible and MS/MS spectra (Table 1 and Figure 3), corresponding to the hydroxycinnamic acid derivatives, 5-caffeoylquinic acid (peak 1), caffeoylquinic acid isomer (peak 2), and chicoric acid (peak 6); two flavonols, quercetin-3-glucoronide (peak 4) and quercetin-hexoside (peak 5); and one anthocyanin, cyanidin-malonylhexoside (peak 3). Similar results were shown by Santander et al. [9] in Grand Rapids and Lollo Bionda lettuce cultivars. On 
the other hand, Llorach et al. [31] determined ten phenolic compounds in two red lettuce cultivars (red oak leaf and Lollo Rosso), highlighting chlorogenic acid, chicoric acid, quercetin-3-glucuronide, and luteolin-7-glucuronide, among others. Furthermore, the authors registered the presence of anthocyanins in the lettuce leaves, but they did not determine the type of anthocyanin. In the same way, the most abundant compounds quantified in our study were 5-caffeoylquinic acid, chicoric acid, and quercetin-hexoside, while caffeoylquinic acid isomer, cyanidin-malonylhexoside, and quercetin-3-glucoronide were detected in lower amounts (Figure 2). Our data are in agreement with those reported by El-Nakhel et al. [32], who found the presence of four phenolic compounds in the red lettuce cultivar Salanova, with chicoric and chlorogenic acids being the most abundant.

Table 1. Identification of phenolic compounds from red lettuce leaves by HPLC-DAD-ESI-MS/MS at 60 days after sowing.

\begin{tabular}{|c|c|c|c|c|c|c|}
\hline Peak & $t R(\min )$ & Identity Assignment & K Max (nm) & $(\mathrm{M})^{+}$ & $(\mathrm{M}-\mathrm{H})^{-}$ & Product Ions $(\mathrm{m} / \mathrm{z})$ \\
\hline 1 & 5.9 & 5-caffeoylquinic acid & 325 & - & 353.6 & 190.6 \\
\hline 2 & 11.0 & Caffeoylquinic acid isomer & 328 & - & 353.1 & 190.7 \\
\hline 3 & 13.1 & Cyanidin-malonylhexoside & 517 & 535.3 & - & $449.0 ; 287.0$ \\
\hline 4 & 14.6 & Quercetin-3-glucoronide & 353 & - & 477.4 & 300.7 \\
\hline 5 & 15.5 & Quercetin-hexoside & 353 & - & 463.0 & 300.7 \\
\hline 6 & 16.1 & Chicoric acid & 330 & - & 473.7 & $310.7 ; 178.8$ \\
\hline
\end{tabular}

Identifications according to Figure 2.

(a)

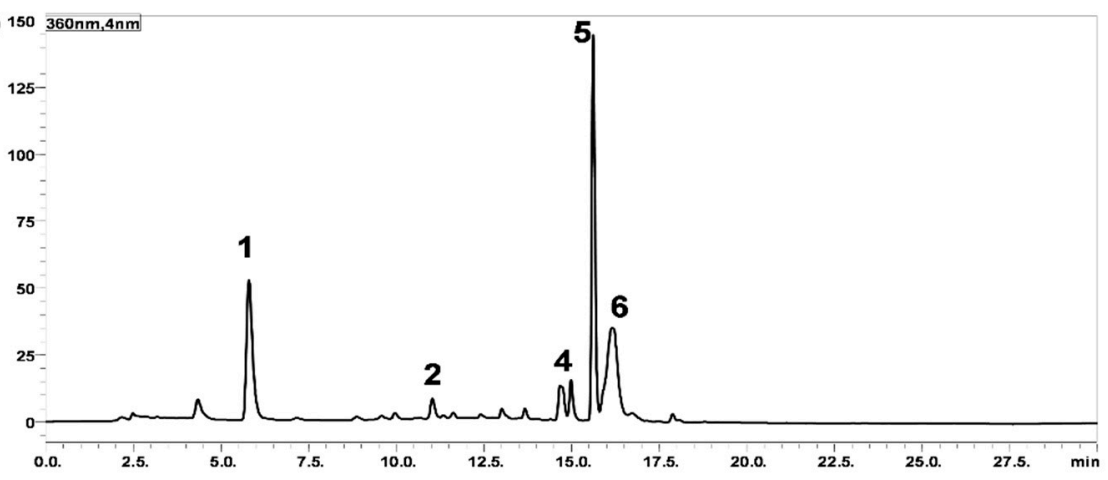

(b)

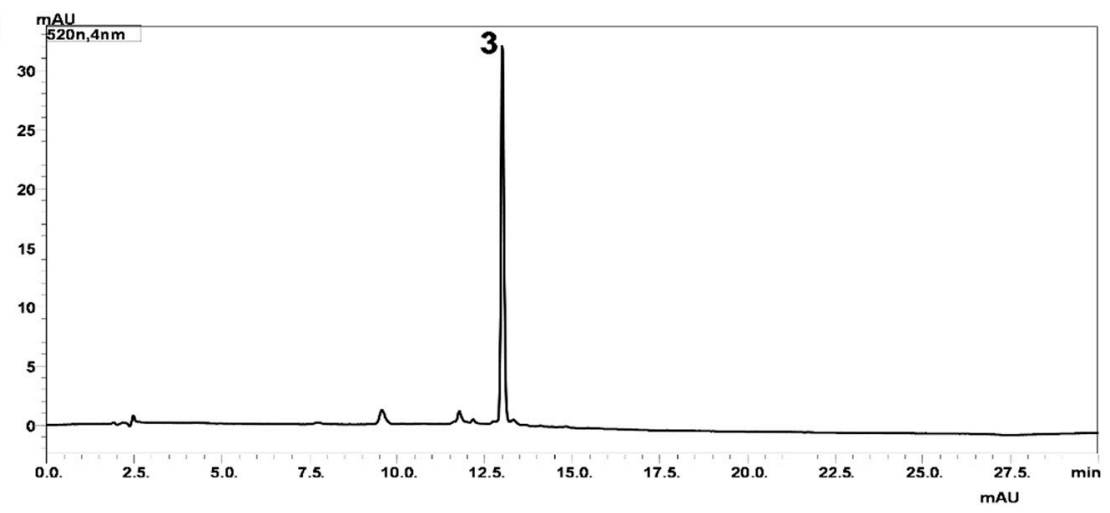

Figure 3. HPLC-DAD chromatogram (360 and $520 \mathrm{~nm}$ ) of phenolic compounds as flavonols, phenolic acids (a) and anthocyanins (b) in lettuce leaves growing under saline conditions. Identifications are according to Table 1.

The exposure to moderate and severe saline stress significantly increased the total phenolic concentrations in the red lettuce leaves compared to the control plants $(0 \mathrm{mM}$ $\mathrm{NaCl}$ ), being higher at 15 days than at 7 days after the application of salinity (Figure 4). In accordance with our results, Mahmoudi et al. [33], found an increase in the total phenolic 
concentration in romaine lettuces when growing for 12 days under $100 \mathrm{mM} \mathrm{NaCl}$ saline stress. In the same way, many studies reported an increase in nutritional and bioactive compounds for hydroponically grown leafy greens (Cichorium spinosum L. and Lactuca sativa L.), triggered by mild-to-moderate $\mathrm{NaCl}$ concentrations in irrigation water [34-37]. In detail, the highest significant values of 5-caffeoylquinic acid and caffeoylquinic acid isomer were recorded in red lettuce plants subjected to severe stress 15 days after the application of salinity (150 to $200 \mathrm{mM} \mathrm{NaCl}$ ), with values ranging from 10.8 to 13.8 and from 1.15 to $1.61 \mathrm{\mu g} \mathrm{g}^{-1} \mathrm{FW}$, respectively (Figure 5a,b). Similarly, quercetin-3-glucuronide reached its highest concentration at severe stress (100 and $150 \mathrm{mM} \mathrm{NaCl}$ ), with values of 1.3 and $1.4 \mu \mathrm{g} \mathrm{g}^{-1} \mathrm{FW}$, respectively (Figure 5d). By contrast, at 15 days after the application of salt, there were no significant differences in quercetin-hexoside concentrations between the control and all the salinity treatments (Figure 5e). However, at 7 days after the application of salt, the plants subjected to severe stress (150 and $200 \mathrm{mM} \mathrm{NaCl}$ ) showed higher concentration compared to the control and the plants subjected to moderate stress $(50 \mathrm{mM} \mathrm{NaCl})$. Here, chicoric acid reached its highest concentrations at 100 and $200 \mathrm{mM}$ $\mathrm{NaCl}$ (severe stress), ranging from 4.33 to $6.67 \mu \mathrm{g} \mathrm{g}^{-1} \mathrm{FW}$ at 7 days after the application of salinity, and from 9.75 to $13.4 \mathrm{\mu g} \mathrm{g}^{-1} \mathrm{FW}$ at 15 days after the application of salinity, respectively (Figure 5f). Our results are in agreement with previous reports by Santander et al. [9], who registered an increase in hydroxycinnamic acid (chicoric acid, 5-caffeoylquinic acid and caffeoylquinic acid isomer) and flavonols (quercetin-hexoside and quercetin-3glucoronide) concentrations in lettuce cultivar Lollo Bionda subjected to $40 \mathrm{mM} \mathrm{NaCl}$. Neocleous et al. [38], showed that a salinity eustress at a dose of 5 to $20 \mathrm{mM} \mathrm{NaCl}$ increased the health-beneficial compounds (flavonoids and total phenolics) in two lettuce cultivars (green cv. "Paris Island" and red cv. "Sanguine"). Furthermore, Borgognone et al. [39], found that antioxidant metabolites, such as phenols, luteolin, cynarine, and chlorogenic acid, in leaves of artichoke and cardoon, were substantially enhanced when subjected to irrigation with a $40 \mathrm{mM} \mathrm{NaCl}$ solution. The increase in the phenolic compounds in vegetable crops is considered of high nutraceutical importance and a high consumption of foods rich in antioxidant compounds has a beneficial effect on human health [40-42].

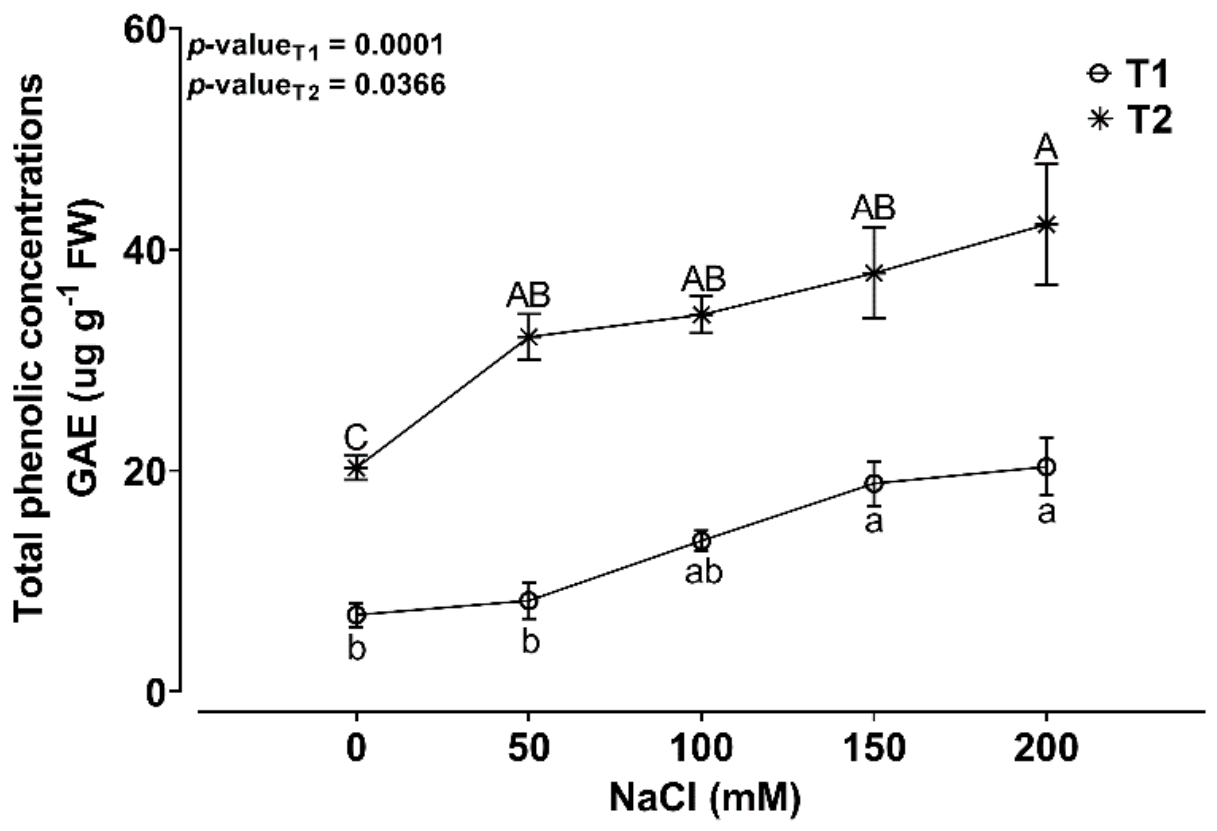

Figure 4. Total phenolic concentration in red lettuce plants (Lactuca sativa Lollo Rosso cv. 'CARMOLI') growing at different saline concentrations in a hydroponic system. T1: total phenols after 7 days of $\mathrm{NaCl}$ application. T2: total phenols after 15 days of $\mathrm{NaCl}$ application. GAE: gallic acids equivalents. Different letters indicate significant differences $(p<0.05)$, according to the Tukey multiple range test $(p<0.05)$ following ANOVA. Data are expressed as mean $\pm \mathrm{SE}, n=6$. 
(a)

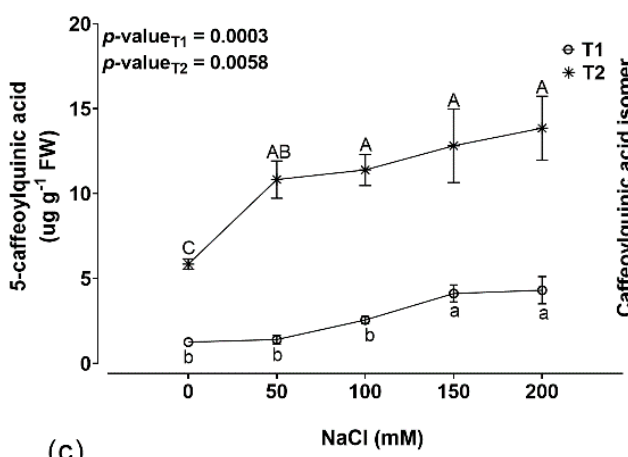

(c)

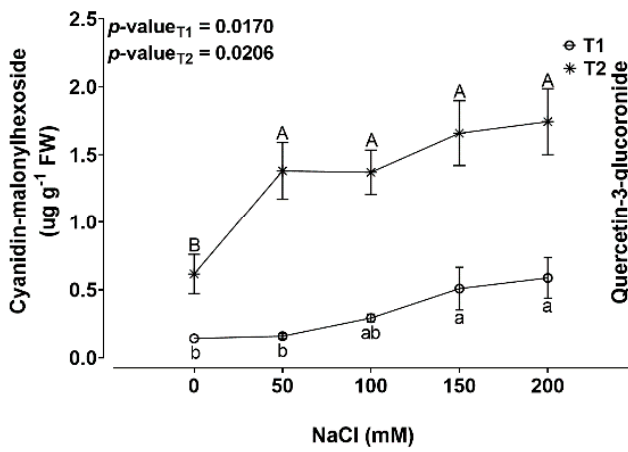

(e)

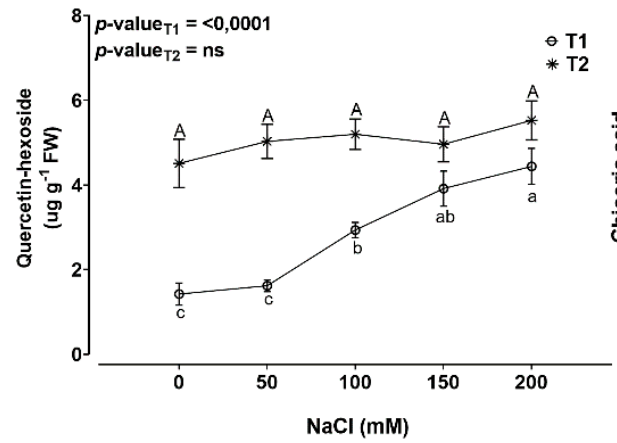

(b)

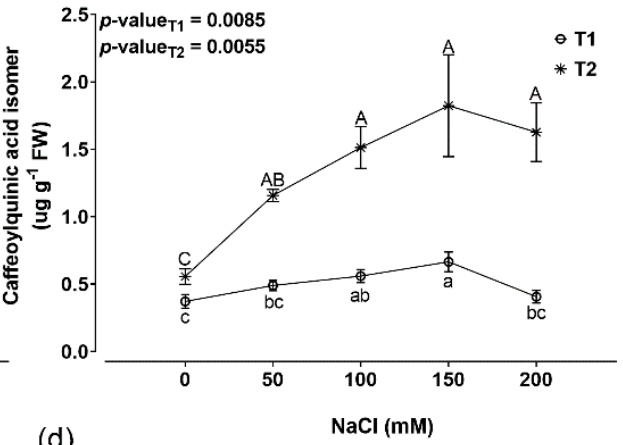

(d)

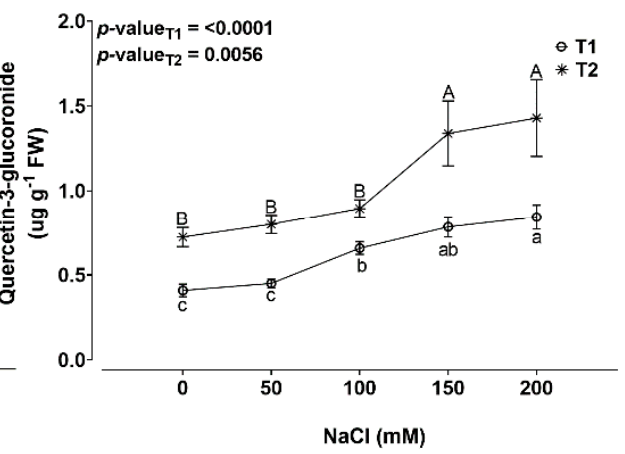

(f)

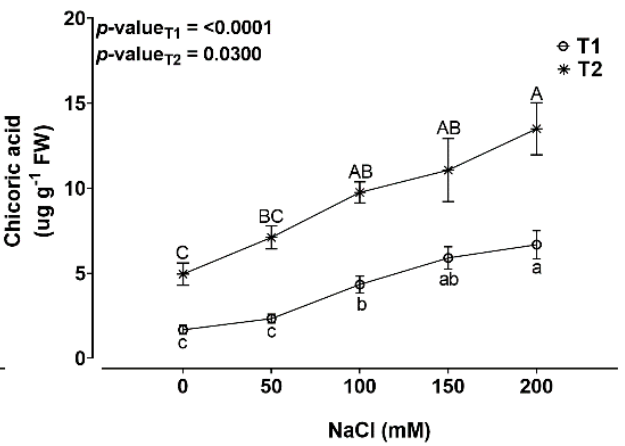

Figure 5. Concentration of 5-caffeoylquinic acid (a), caffeoylquinic acid isomer (b), cyanidinmalonylhexoside (c), quercetin-3-glucoronide (d), quercetin-hexoside (e), and chicoric acid (f) in red lettuce plants (Lactuca sativa Lollo Rosso cv. 'CARMOLI') growing at different saline concentrations in a hydroponic system. T1: concentrations after 7 days of $\mathrm{NaCl}$ application. T2: concentrations after 15 days of $\mathrm{NaCl}$ application. Different letters indicate significant differences $(p<0.05)$, according to the Tukey multiple range test $(p<0.05)$ following ANOVA. Data are expressed as mean $\pm \mathrm{SE}, n=6$.

Anthocyanins are a class of water-soluble phenolic compounds with strong antioxidant activity [43]. These play an important role in human health by preventing neuronal and cardiovascular diseases, reducing diabetes risk, and exhibiting anti-cancer activity [44]. The accumulation of anthocyanins in lettuce is responsible for the red color of the leaves and the amount of accumulation determines the intensity and degree of redness [45]. In this study, cyanidin-malonylhexoside was the main anthocyanin identified in the Lollo Rosso lettuce leaves. The MS data of anthocyanin identified in our study are similar to the MS data of the major anthocyanin (cyanidin 3-(6"-malonoyl)glucoside) found in red lettuce by $\mathrm{Wu}$ and Prior [45]. In addition, cyanidin 3-(6"-malonoyl)glucoside has potent radical scavenging activity [46]. In our study, cyanidin-malonylhexoside levels were significantly increased under moderate and severe stress, with values ranging from 1.38 to $1.74 \mu \mathrm{g} \mathrm{g}^{-1}$ FW at 15 days after the application of salinity (Figure 5c). Similar results were found by Sakamoto et al. [47], who reported that red lettuce plants cv. mother-red reached higher anthocyanin values when irrigated with saline water. 
Plants subjected to saline stress produce an increase in the production of ROS, generating oxidative stress [9]. Due to the significant antioxidant activity of phenolic compounds, the increase in their levels in plants growing under salinity is related to the ROS-scavenging mechanisms of plants [48]. In this sense, DPPH activity is a key trait associated with the antioxidant potential of the phenolic compounds present in vegetable foods [49]. In our study, the DPPH radical scavenging potential was significantly increased by salinity 7 days after its application (Figure 6). At this point, the greatest scavenging potential was recorded in lettuce plants subjected to severe saline stress $(200 \mathrm{mM} \mathrm{NaCl})$, with values 1.69- and 1.66-fold higher than those of the control plants and plants subjected to moderate saline stress $(50 \mathrm{mM} \mathrm{NaCl})$, respectively. In this regard, several studies have shown an increment of DPPH antioxidant activity when phenolic concentration and total flavonoid concentration increase [46,50]. By contrast, at 15 days after salinity application, the DPPH scavenging potential reached its highest value in the lettuce plants subjected to moderate saline stress $\left(11.8 \mu \mathrm{mol} \mathrm{g}^{-1} \mathrm{FW} ; 50 \mathrm{mM} \mathrm{NaCl}\right)$. However, the DPPH scavenging potential significantly diminished when the plants grown under severe saline stress, with values of 8.4 and $7.9 \mu \mathrm{mol} \mathrm{g}^{-1} \mathrm{FW}$ at 150 and $200 \mathrm{mM} \mathrm{NaCl}$, respectively (Figure 6), even though the total phenol concentrations were increased (Figure 4). Moreover, cyanidins are the most potent scavengers of DPPH radicals in red lettuce, showing significantly higher radicalquenching activity than in green lettuces, making red lettuce a food with higher nutritional value, since its consumption can minimize oxidative-stress-related diseases [46].

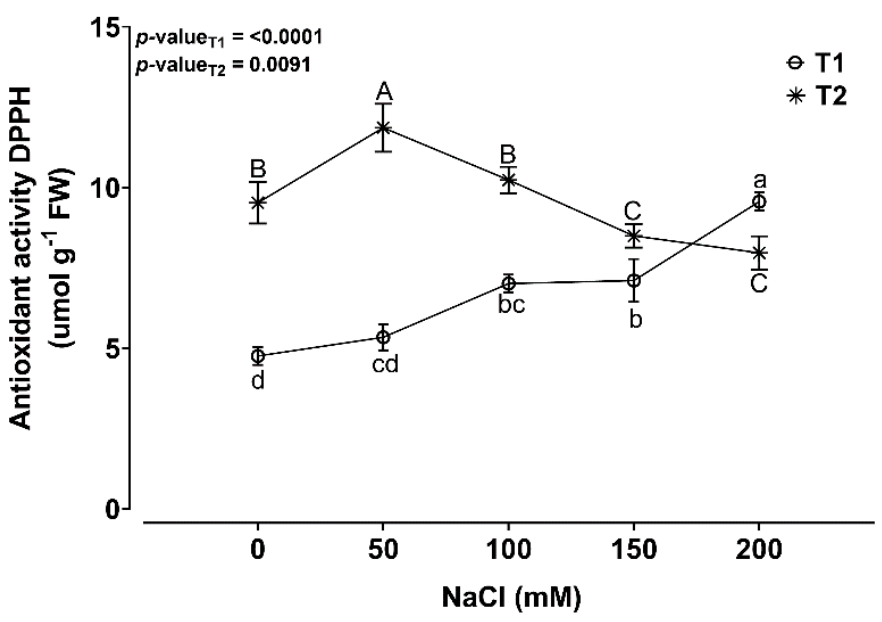

Figure 6. Antioxidant activity (DPPH) in red lettuce plants (Lactuca sativa Lollo Rosso cv. 'CARMOLI') growing at different saline concentrations in a hydroponic system. T1: total phenols after 7 days of $\mathrm{NaCl}$ application. T2: total phenols after 15 days of $\mathrm{NaCl}$ application. Different letters indicate significant differences $(p<0.05)$, according to the Tukey multiple range test $(p<0.05)$ following ANOVA. Data are expressed as mean $\pm \mathrm{SE}, n=6$.

The principal components (PC) analysis evidenced the formation of two highly independent groups, in accordance with the distribution of the experimental variables in the two PCs. In detail, PC1 explained $63.5 \%$ and PC2 $13.8 \%$ of the total experimental variance (Figure 7). PC1 was positively influenced by the 5-caffeoylquinic acid, caffeoylquinic acid isomer, cyanidin-malonylhexoside, quercetin-3-glucoronide, quercetin-hexoside, chicoric acid, and total phenols concentrations determined at 7 and 15 days after salt application, as well as DPPH antioxidant activity determined at 7 days after salt application. Furthermore, PC1 was negatively related to shoot and root biomass production, the efficiency of photosystem II (ФPSII), and the DPPH antioxidant activity determined at 15 days after salt application. To a lesser extent, PC2 was positively influenced by quercetin-hexoside, chicoric acid, 5-caffeoylquinic acid, and total phenol concentrations (Figure 7a). The PC analysis, together with the cluster analysis, differentiated three well-defined groups (Figure $7 \mathrm{~b}$ ). The first group corresponded with the control plants and the plants subjected 
to $50 \mathrm{mM} \mathrm{NaCl}$; the second group included the plants subjected to $100 \mathrm{mM} \mathrm{NaCl}$; and the third group corresponded with the plants subjected to 150 and $200 \mathrm{mM} \mathrm{NaCl}$. The loading plot, and consequently, cluster analysis, showed that biomass production was strongly correlated with $\Phi$ PSII, and that both were strongly correlated with the DPPH antioxidant activity determined at 15 days after salt application. These results suggest that phenolic compounds may have had the strongest effect, measured as DPPH radical scavenging between 50 and $100 \mathrm{mM} \mathrm{NaCl}$, on decreasing antioxidant activity under severe saline stress (150 and $200 \mathrm{mM} \mathrm{NaCl}$ ). The third group included the plants subjected to 150 and $200 \mathrm{mM}$ $\mathrm{NaCl}$ and represented the plants that reached higher phenolic concentration. However, this group also showed the lowest DPPH antioxidant activity at 15 days after the application of salinity and, consequently, a lower $\Phi$ PSII and diminished biomass production.
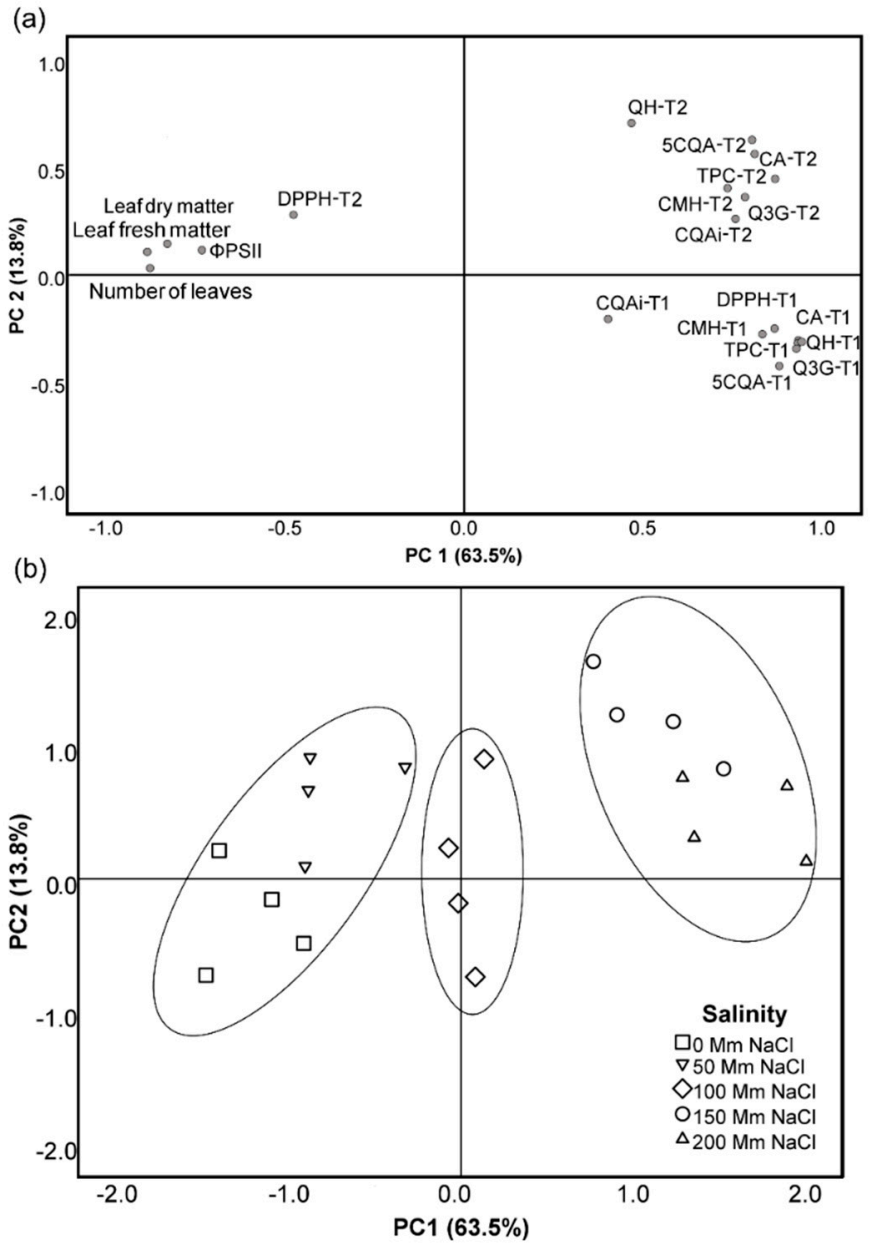

Figure 7. (a) Principal component loading plot (PCA) of biomass production, efficiency of photosystem II (ФPSII), phenolic compounds, and DPPH antioxidant activity of red lettuce plants (Lactuca sativa Lollo Rosso cv. 'CARMOLI') growing at different saline concentrations in a hydroponic system $(0,50,100,150$, and $200 \mathrm{mM} \mathrm{NaCl})$. 5CQA: 5-caffeoylquinic acid; QH: quercetin-hexoside; CA: chicoric acid; CMH: cyanidin-malonylhexoside; Q3G: quercetin-3-glucoronide; CQAi: caffeoylquinic acid isomer. T1: sampled after 7 days of $\mathrm{NaCl}$ application. T2: sampled after 15 days of $\mathrm{NaCl}$ application. The mean value was used in each situation. Percentage values in parentheses indicate the variation explained by each PC. (b) Cluster analysis for the experiment. The circles comprise individuals with similar characteristics according to the analysis and should be considered as a visual aid for discrimination of groups.

\section{Conclusions}

The application of different eustress techniques, such as mild and moderate saline stress, should be useful to the enhancement of the nutritional and functional attributes 
of vegetables without compromising yield. In this regard, our study showed that the application of moderate salt stress $(50 \mathrm{mM} \mathrm{NaCl})$ application fifteen days in red lettuce grown in a hydroponic system induced the stimulation of the biosynthesis of polyphenols and flavonoids, and improved antioxidant activity while increasing DPPH scavenging capacity without significantly affecting the growth and biomass production of lettuce plants (Lactuca sativa Lollo Rosso cv. 'CARMOLI'). Conversely, when severe salt stress (150-200 mM NaCl) was applied, a similar increase in phenolic compound levels was produced, but concomitantly with a decrease in the biomass production. In this way, the high levels of nutritionally valuable antioxidant substances and the significantly higher radical scavenging activity in red lettuce give it greater nutritional value. Finally, the principal challenges for future research in vegetables crops are the application of eustressors during specific phenological stages, the study of the type of salt source and concentrations to be applied, and a consideration of the use of different unconventional water resources, such as saline water or wastewater, to produce moderate and controlled saline stress in agriculture crops, as well as researching the increase in their bioactive compounds.

Author Contributions: Methodology, C.S., G.V. and A.R.; validation, G.V. and P.C.; formal analysis, C.S. and A.R.; investigation, C.S. and C.V.; data curation, C.S. and P.C.; writing-original draft preparation, C.S.; writing—review and editing, G.V., A.R., C.V. and P.C.; supervision, P.C.; project administration, P.C.; funding acquisition, C.S. and P.C. All authors have read and agreed to the published version of the manuscript.

Funding: This research was funded by Agencia Nacional de Desarrollo (ANID), through the grants ANID/FONDECYT/3210588, ANID/FONDAP/15130015, ANID/FONDECYT 1190585, and ANID/FONDECYT/1210964, and the Chilean Ministry of Education (MINEDUC Chile) through the InES19 project, code FRO19101.

Conflicts of Interest: The authors declare no conflict of interest.

\section{References}

1. Wang, L.; Chen, J.; Xie, H.; Ju, X.; Liu, R.H. Phytochemical profiles and antioxidant activity of adlay varieties. J. Agric. Food Chem. 2013, 61, 5103-5113. [CrossRef] [PubMed]

2. Kamiloglu, S.; Tomas, M.; Ozdal, T.; Yolci-Omeroglu, P.; Capanoglu, E. Chapter 2-Bioactive Component Analysis. In Innovative Food Analysis; Galanakis, C.M., Ed.; Academic Press: Cambridge, MA, USA, 2021; pp. 41-65, ISBN 9780128194935.

3. Sawatdee, S.; Prommuak, C.; Jarunglumlert, T.; Pavasant, P.; Flood, A.E. Combined effects of cations in fertilizer solution on antioxidant content in red lettuce (Lactuca sativa L.). J. Sci. Food Agric. 2021, 101, 4632-4642. [CrossRef] [PubMed]

4. Zhang, Y.; Gan, R.Y.; Li, S.; Zhou, Y.; Li, A.N.; Xu, D.P.; Li, H.B.; Kitts, D.D. Antioxidant phytochemicals for the prevention and treatment of chronic diseases. Molecules 2015, 20, 21138-21156. [CrossRef] [PubMed]

5. Zhang, L.; Martinelli, E.; Senizza, B.; Miras-Moreno, B.; Yildiztugay, E.; Arikan, B.; Elbasan, F.; Ak, G.; Balci, M.; Zengin, G.; et al. The combination of mild salinity conditions and exogenously applied phenolics modulates functional traits in lettuce. Plants 2021, 10, 1457. [CrossRef] [PubMed]

6. Chu, Y.-F.; Sun, J.; Wu, X.; Liu, R.H. Antioxidant and antiproliferative activities of common vegetables. J. Agric. Food Chem. 2002, 50, 6910-6916. [CrossRef]

7. Caldwell, C.R. Alkylperoxyl radical scavenging activity of red leaf lettuce (Lactuca sativa L.) phenolics. J. Agric. Food Chem. 2003, 51, 4589-4595. [CrossRef]

8. Liu, X.; Ardo, S.; Bunning, M.; Parry, J.; Zhou, K.; Stushnoff, C.; Stoniker, F.; Yu, L.; Kendall, P. Total phenolic content and DPPH radical scavenging activity of lettuce (Lactuca sativa L.) grown in Colorado. LWT-Food Sci. Technol. 2007, 40, 552-557. [CrossRef]

9. Santander, C.; Ruiz, A.; García, S.; Aroca, R.; Cumming, J.; Cornejo, P. Efficiency of two arbuscular mycorrhizal fungal inocula to improve saline stress tolerance in lettuce plants by changes of antioxidant defense mechanisms. J. Sci. Food Agric. 2020, 100, 1577-1587. [CrossRef]

10. Degl'Innoocenti, E.; Pardossi, A.; Tattini, M.; Guidi, L. Phenolic compounds and antioxidant power in minimally processed salad. J. Food Biochem. 2008, 32, 642-653. [CrossRef]

11. Oh, M.M.; Carey, E.E.; Rajashekar, C.B. Environmental stresses induce health-promoting phytochemicals in lettuce. Plant Physiol. Biochem. 2009, 47, 578-583. [CrossRef]

12. Materska, M.; Olszówka, K.; Chilczuk, B.; Stochmal, A.; Pecio, Ł.; Pacholczyk-Sienicka, B.; Piacente, S.; Pizza, C.; Masullo, M. Polyphenolic profiles in lettuce (Lactuca sativa L.) after $\mathrm{CaCl}_{2}$ treatment and cold storage. Eur. Food Res. Technol. 2019, 245, 733-744. [CrossRef]

13. Rouphael, Y.; Petropoulos, S.A.; Cardarelli, M.; Colla, G. Salinity as eustressor for enhancing quality of vegetables. Sci. Hortic. 2018, 234, 361-369. [CrossRef] 
14. Petridis, A.; Therios, I.; Samouris, G.; Tananaki, C. Salinity-induced changes in phenolic compounds in leaves and roots of four olive cultivars (Olea europaea L.) and their relationship to antioxidant activity. Environ. Exp. Bot. 2012, 79, 37-43. [CrossRef]

15. Orsini, F.; Maggio, A.; Rouphael, Y.; De Pascale, S. “Physiological quality” of organically grown vegetables. Sci. Hortic. 2016, 208, 131-139. [CrossRef]

16. Baenas, N.; García-Viguera, C.; Moreno, D.A. Elicitation: A tool for enriching the bioactive composition of foods. Molecules 2014, 19, 13541-13563. [CrossRef]

17. Colla, G.; Rouphael, Y.; Cardarelli, M.; Svecova, E.; Rea, E.; Lucini, L. Effects of saline stress on mineral composition, phenolic acids and flavonoids in leaves of artichoke and cardoon genotypes grown in floating system. J. Sci. Food Agric. 2013,93, 1119-1127. [CrossRef]

18. Hoagland, D.R.; Arnon, D.I. The Water-Culture Method for Growing Plants without Soil; The College of Agriculture, University of California: Berkeley, CA, USA, 1950; Volume 347.

19. Parada, J.; Valenzuela, T.; Gómez, F.; Tereucán, G.; García, S.; Cornejo, P.; Winterhalter, P.; Ruiz, A. Effect of fertilization and arbuscular mycorrhizal fungal inoculation on antioxidant profiles and activities in Fragaria ananassa fruit. J. Sci. Food Agric. 2019, 99, 1397-1404. [CrossRef]

20. Ruiz, A.; Aguilera, A.; Ercoli, S.; Parada, J.; Winterhalter, P.; Contreras, B.; Cornejo, P. Effect of the frying process on the composition of hydroxycinnamic acid derivatives and antioxidant activity in flesh-colored potatoes. Food Chem. 2018, 268, 577-584. [CrossRef]

21. Singleton, V.L.; Rossi, J.A. Colorimetry of total phenolics with phosphomolybdic-phosphotungstic acid reagents. Am. J. Enol. Vitic. 1965, 16, 144-158.

22. Vázquez-Hernández, M.C.; Parola-Contreras, I.; Montoya-Gómez, L.M.; Torres-Pacheco, I.; Schwarz, D.; Guevara-González, R.G. Eustressors: Chemical and physical stress factors used to enhance vegetables production. Sci. Hortic. 2019 , 250, $223-229$. [CrossRef]

23. Al-Maskri, A.; Al-Kharusi, L.; Al-Miqbali, H.; Khan, M.M. Effects of salinity stress on growth of lettuce (Lactuca sativa) under closed-recycle nutrient film technique. Int. J. Agric. Biol. 2010, 12, 377-380.

24. Santander, C.; Sanhueza, M.; Olave, J.; Borie, F.; Valentine, A.; Cornejo, P. Arbuscular mycorrhizal colonization promotes the tolerance to salt stress in lettuce plants through an efficient modification of ionic balance. J. Soil Sci. Plant Nutr. 2019, 19, 321-331. [CrossRef]

25. Santander, C.; Aroca, R.; Cartes, P.; Vidal, G.; Cornejo, P. Aquaporins and cation transporters are differentially regulated by two arbuscular mycorrhizal fungi strains in lettuce cultivars growing under salinity conditions. Plant Physiol. Biochem. 2021, 158, 396-409. [CrossRef]

26. Shin, Y.K.; Bhandari, S.R.; Jo, J.S.; Song, J.W.; Cho, M.C.; Yang, E.Y.; Lee, J.G. Response to salt stress in lettuce: Changes in chlorophyll fluorescence parameters, phytochemical contents, and antioxidant activities. Agronomy 2020, 10, 1627. [CrossRef]

27. Allel, D.; Ben-Amar, A.; Abdelly, C. Leaf photosynthesis, chlorophyll fluorescence and ion content of barley (Hordeum vulgare) in response to salinity. J. Plant Nutr. 2018, 41, 497-508. [CrossRef]

28. Chaves, M.M.; Flexas, J.; Pinheiro, C. Photosynthesis under drought and salt stress: Regulation mechanisms from whole plant to cell. Ann. Bot. 2009, 103, 551-560. [CrossRef]

29. Saddiq, M.S.; Iqbal, S.; Hafeez, M.B.; Ibrahim, A.M.H.; Raza, A.; Fatima, E.M.; Baloch, H.; Jahanzaib; Woodrow, P.; Ciarmiello, L.F. Effect of salinity stress on physiological changes in winter and spring wheat. Agronomy 2021, 11, 1193. [CrossRef]

30. Baker, N.R.; Rosenqvist, E. Applications of chlorophyll fluorescence can improve crop production strategies: An examination of future possibilities. J. Exp. Bot. 2004, 55, 1607-1621. [CrossRef]

31. Llorach, R.; Martínez-Sánchez, A.; Tomás-Barberán, F.A.; Gil, M.I.; Ferreres, F. Characterisation of polyphenols and antioxidant properties of five lettuce varieties and escarole. Food Chem. 2008, 108, 1028-1038. [CrossRef]

32. El-Nakhel, C.; Pannico, A.; Kyriacou, M.C.; Giordano, M.; De Pascale, S.; Rouphael, Y. Macronutrient deprivation eustress elicits differential secondary metabolites in red and green-pigmented butterhead lettuce grown in a closed soilless system. J. Sci. Food Agric. 2019, 99, 6962-6972. [CrossRef]

33. Mahmoudi, H.; Huang, J.; Gruber, M.Y.; Kaddour, R.; Lachaâl, M.; Ouerghi, Z.; Hannoufa, A. The impact of genotype and salinity on physiological function, secondary metabolite accumulation, and antioxidative responses in lettuce. J. Agric. Food Chem. 2010, 58, 5122-5130. [CrossRef] [PubMed]

34. Klados, E.; Tzortzakis, N. Effects of substrate and salinity in hydroponically grown Cichorium spinosum. J. Soil Sci. Plant Nutr. 2014, 14, 211-222. [CrossRef]

35. Petropoulos, S.A.; Levizou, E.; Ntatsi, G.; Fernandes, Â.; Petrotos, K.; Akoumianakis, K.; Barros, L.; Ferreira, I.C.F.R. Salinity effect on nutritional value, chemical composition and bioactive compounds content of Cichorium spinosum L. Food Chem. 2017, 214, 129-136. [CrossRef] [PubMed]

36. Bonasia, A.; Lazzizera, C.; Elia, A.; Conversa, G. Nutritional, biophysical and physiological characteristics of wild rocket genotypes as affected by soilless cultivation system, salinity level of nutrient solution and growing period. Front. Plant Sci. 2017, 8, 300. [CrossRef]

37. Conversa, G.; Bonasia, A.; Lazzizera, C.; Elia, A. Soilless cultivation system, electrical conductivity of nutrient solution, and growing season on yield and quality of baby-leaf oak-leaf lettuce. Agronomy 2021, 11, 1220. [CrossRef] 
38. Neocleous, D.; Koukounaras, A.; Siomos, A.S.; Vasilakakis, M. Assessing the salinity effects on mineral composition and nutritional quality of green and red "Baby" Lettuce. J. Food Qual. 2014, 37, 1-8. [CrossRef]

39. Borgognone, D.; Cardarelli, M.; Rea, E.; Lucini, L.; Colla, G. Salinity source-induced changes in yield, mineral composition, phenolic acids and flavonoids in leaves of artichoke and cardoon grown in floating system. J. Sci. Food Agric. 2014, 94, 1231-1237. [CrossRef]

40. Rouphael, Y.; Cardarelli, M.; Lucini, L.; Rea, E.; Colla, G. Nutrient solution concentration affects growth, mineral composition, phenolic acids, and flavonoids in leaves of artichoke and cardoon. HortScience 2012, 47, 1424-1429. [CrossRef]

41. Rouphael, Y.; Kyriacou, M.C.; Petropoulos, S.A.; De Pascale, S.; Colla, G. Improving vegetable quality in controlled environments. Sci. Hortic. 2018, 234, 275-289. [CrossRef]

42. Justesen, U.; Knuthsen, P. Composition of flavonoids in fresh herbs and calculation of flavonoid intake by use of herbs in traditional Danish dishes. Food Chem. 2001, 73, 245-250. [CrossRef]

43. Bu, C.; Zhang, Q.; Zeng, J.; Cao, X.; Hao, Z.; Qiao, D.; Cao, Y.; Xu, H. Identification of a novel anthocyanin synthesis pathway in the fungus Aspergillus sydowii H-1. BMC Genom. 2020, 21, 29. [CrossRef] [PubMed]

44. Yousuf, B.; Gul, K.; Wani, A.A.; Singh, P. Health benefits of anthocyanins and their encapsulation for potential use in food systems: A Review. Crit. Rev. Food Sci. Nutr. 2016, 56, 2223-2230. [CrossRef]

45. $\mathrm{Wu}, \mathrm{X}$; Prior, R.L. Identification and characterization of anthocyanins by high-performance liquid chromatography-electrospray ionization-tandem mass spectrometry in common foods in the United States: Vegetables, nuts, and grains. J. Agric. Food Chem. 2005, 53, 3101-3113. [CrossRef] [PubMed]

46. Kim, D.-E.E.; Shang, X.; Assefa, A.D.; Keum, Y.-S.S.; Saini, R.K. Metabolite profiling of green, green/red, and red lettuce cultivars: Variation in health beneficial compounds and antioxidant potential. Food Res. Int. 2018, 105, 361-370. [CrossRef]

47. Sakamoto, K.; KoGI, M.; Yanagisawa, T. Effects of salinity and nutrients in seawater on hydroponic culture of red leaf lettuce. Environ. Control Biol. 2014, 52, 189-195. [CrossRef]

48. Ayuso-Calles, M.; García-Estévez, I.; Jiménez-Gómez, A.; Flores-Félix, J.D.; Teresa Escribano-Bailón, M.; Rivas, R. Rhizobium laguerreae improves productivity and phenolic compound content of lettuce (Lactuca sativa L.) under saline stress conditions. Foods 2020, 9, 1166. [CrossRef] [PubMed]

49. Chung, I.M.; Lim, J.J.; Ahn, M.S.; Jeong, H.N.; An, T.J.; Kim, S.H. Comparative phenolic compound profiles and antioxidative activity of the fruit, leaves, and roots of korean ginseng (Panax ginseng meyer) according to cultivation years. J. Ginseng Res. 2016, 40, 68-75. [CrossRef]

50. Aryal, S.; Baniya, M.K.; Danekhu, K.; Kunwar, P.; Gurung, R.; Koirala, N. Total Phenolic content, flavonoid content and antioxidant potential of wild vegetables from western Nepal. Plants 2019, 8, 96. [CrossRef] [PubMed] 